\title{
A EDUCAÇÃO FEMININA NA PERSPECTIVA DE AGÊNCIAS MULTILATERAIS
}

Leda Aparecida Vanelli Nabuco de Gouvêa Universidade Estadual do Oeste do Paraná

Amélia Kimiko Noma Universidade Estadual de Maringá

\section{RESUMO}

Este artigo aborda as proposições concernentes à educação feminina constantes em documentos produzidos, a partir de 1990, pelas agências multilaterais: UNESCO, UNICEF, Banco Mundial e Cepal. O objetivo é investigar as funções de reparação, equalização e qualificação atribuídas à educação feminina, às quais são incorporadas preocupações econômicas, morais e éticas no combate à pobreza. Agrega ao debate a discussão sobre a funcionalidade ideológica assumida pela referida educação. Argumenta que a defesa da educação feminina está a legitimar a implementação de políticas neoliberais e expressa a busca de soluções para os problemas e contradições gerados estruturalmente pelo capitalismo, por intermédio de ajustes feitos estritamente nos efeitos e nas consequências.

Palavras-chave: Educação feminina; Políticas educacionais; Agências multilaterais; Políticas neoliberais.

\section{WOMEN EDUCATION FROM THE PERSPECTIVE OF MULTILATERAL AGENCIES}

\begin{abstract}
This article approach the propositions concerning the female education contained in documents produced, from 1990, the multilateral agencies: UNESCO, Unicef, World Bank and Eclac. The goal is to investigate the functions of repair, equalization and qualification assigned to the female education, which are incorporated concerns economic, moral and ethical to combat to the poverty. Add to the debate a discussion on the functionality assumed by that ideological education. It argues that the defence of female education is legitimize the implementation of neoliberal policies and expressed the search for solutions to the problems and contradictions structurally generated by capitalism, through adjustments made strictly on the effects and the consequences.

Keywords: Education female; Educational policies, multilateral agencies; neoliberal policies.
\end{abstract}

\section{Introdução}

O presente artigo aborda a educação formal de mulheres e meninas na perspectiva das seguintes organizações multilaterais: a Organização das Nações Unidas para a Educação, a Ciência e a Cultura (UNESCO), o Fundo das Nações Unidas para a Infância (UNICEF), o Banco Mundial (BM) e a Comissão Econômica para a América Latina e Caribe (Cepal). 
Com fundamento na análise de conteúdo de fontes documentais produzidas no âmbito das referidas agências a partir de 1990, busca-se explicitar e sintetizar seus posicionamentos concernentes à política para a educação feminina, com vistas à apreensão de que funcionalidade é atribuída à educação de mulheres e meninas. Indaga-se sobre o significado histórico das, aqui denominadas, funções de reparação, de equalização e de qualificação atribuídas à educação feminina e às quais são incorporadas preocupações econômicas, morais e éticas de combate à pobreza, produção da equidade, justiça social, entre outras. Outrossim argumenta que, para além das referidas funções, há uma funcionalidade ideológica que prima por legitimar as políticas de cunho neoliberal.

A fim de dar conta do objetivo proposto, este trabalho se ancora na análise de conteúdo dos documentos selecionados e realiza um diálogo crítico com as fontes, problematizando os dados à luz da literatura existente. Os documentos são abordados como objeto de interpretação, como unidades de análise que possibilitam o acesso ao discurso para a apreensão de sua política, por conterem diagnósticos, prioridades, direcionamentos e orientações para a agenda política dos países membros da Organização das Nações Unidas (SHIROMA; CAMPOS; GARCIA, 2005).

\section{A educação feminina na ótica da UNESCO}

A UNESCO, como agência especializada da Organização das Nações Unidas (ONU), tem por missão institucional trabalhar pela construção da paz e da seguridade, promovendo a colaboração entre as nações por meio da educação, da ciência e da cultura. A partir dos anos 1990, sua atuação na área educacional tem se pautado pela diretriz do movimento internacional de educação para todos, resultante de uma parceria entre várias agências multilaterais. A importância que a questão da educação de mulheres e meninas assumiu, no período considerado, aparece como ponto nodal para as ações políticas dos vários países-membros da UNESCO, podendo ser constatado tanto nos instrumentos jurídicos, representados pelas convenções e tratados internacionais, quanto nas muitas declarações formuladas a partir dos anos de 1990. Dentre os documentos produzidos pela UNESCO, neste artigo, utilizam-se aqueles elaborados em conferências e fóruns internacionais sobre educação, o Relatório Jacques Delors, Estratégia a Médio Prazo para 2002-2007 e o Relatório de Monitoramento Global 2003/2004, denominado Gênero e educação para todos: o salto para a igualdade.

O marco das orientações políticas que prioriza a educação das mulheres e meninas foi a Declaração Mundial sobre Educação para Todos: satisfação das necessidades básicas de aprendizagem, elaborada na Conferência Mundial sobre Educação para Todos, realizada em Jomtien no ano de 1990. Neste documento, registrou-se que mais de cem milhões de crianças, das quais pelo menos sessenta milhões de meninas, não tinham acesso ao ensino primário, mais de 960 milhões de adultos eram analfabetos e dois terços daquele total eram mulheres. Diante deste quadro, estabeleceu-se, no Artigo $3^{\circ}$, intitulado "Universalizar o acesso à educação e promover a equidade", a prioridade urgente de melhorar a qualidade e garantir o acesso à educação para meninas e mulheres, superando todos os obstáculos que impedem sua participação ativa no processo educativo, e os preconceitos e estereótipos de qualquer natureza devem ser eliminados da educação (UNESCO, 1990).

Nos eventos educacionais que se seguiram nos anos 1990, patrocinados por agências multilaterais, entre elas a UNESCO, a educação feminina foi reafirmada como um elemento-chave para o processo de desenvolvimento do bem-estar social. Estes eventos foram: Conferência de Nova Delhi, realizada em 1993; V Conferência Internacional de 
Educação de Adultos (CONFITEA V), realizada em 1997, e Cúpula Mundial de Educação, realizada em Dacar, Senegal, 2000. Neste último evento, foi produzido o Marco de Ação de Dacar, Educação para todos: atingindo nossos compromissos coletivos, em que se firmaram compromissos para que seis objetivos educacionais fossem alcançados, dos quais três remetem à educação de mulheres e meninas. São eles: assegurar que todas as crianças, com ênfase especial nas meninas e crianças em circunstâncias difíceis, tenham acesso à educação básica, obrigatória, gratuita e de boa qualidade até o ano de 2015; melhoria de $50 \%$ nos níveis de alfabetização de adultos, especialmente das mulheres, até 2015, e eliminar a disparidade de gênero na educação primária e secundária até 2005; promoção da igualdade de gênero na educação, aprazado também para o ano de 2015. Para atingir os objetivos relacionados às meninas e mulheres, propôs-se a implementação de estratégias integradas para promover a equidade de gênero na educação, reconhecendo-se a necessidade de mudanças de atitudes, valores e práticas (UNESCO/CONSED, 2001).

Depreende-se, dos documentos acordados nos eventos acima identificados, que deve ser pauta necessária, na agenda política dos governos dos Estados-Membros, reparar a dívida social com as mulheres e meninas, visando ao objetivo de equalizar as distorções educacionais existentes entre mulheres e homens. Esta discussão foi também contemplada no Relatório para a UNESCO da Comissão Internacional sobre Educação para o Século XXI, publicado em 1996, com o título Educação: um tesouro a descobrir, também conhecido como Relatório Jacques Delors. Neste documento, embora não contenha diretrizes políticas específicas para a educação de meninas e mulheres, podem ser encontradas algumas considerações sobre a educação feminina. Uma delas é que a educação das mulheres e das jovens é um dos melhores investimentos para o futuro, visto resultar em melhorias nas condições de saúde da família e na escolarização das crianças, "[...] é educando as mães e promovendo, de um modo geral, a condição feminina que as sociedades terão mais probabilidades de ver coroados de êxitos os seus esforços" (DELORS, 2000, p. 198). Neste Relatório, além das suas considerações sobre as consequências da discriminação feminina na educação, há referência à pertinência da qualificação das mulheres para o desenvolvimento, notadamente ao aludir sobre a função da mulher na esfera da reprodução social.

A inclusão da educação das mulheres e meninas na programação de trabalho da UNESCO também recebeu atenção especial. Os planos sexenais e bienais da agência documentos que orientam as suas atividades e tratam de sua programação de trabalho incluíram, em seus dispositivos, procedimentos em relação às mulheres, especialmente a educação. O documento Estratégia a Médio Prazo: (2002 - 2007), na Declaração do Milênio, aprovada pela ONU em setembro de 2000, é considerado o guia geral para as suas atividades de trabalho, o que conduz a mesma a participar das ações relativas à erradicação da pobreza. A justificativa central para o direcionamento das atividades da agência para a erradicação da pobreza parte da consideração de que cerca da metade da humanidade procura sobreviver com menos de dois dólares por dia e uma quarta parte vive marginalizada com menos de um dólar ao dia - setenta por cento dos pobres são mulheres e duas terças partes têm menos de 15 anos de idade (UNESCO, 2002).

O documento da UNESCO (2002, p. 5) expõe que uma das novas tarefas da organização é a obtenção de "[...] um consenso internacional em torno das normas e princípios que são necessários para responder aos novos desafios e dilemas éticos derivados da mundialização". Afirma pretender criar um vínculo entre o seu mandato e suas funções e a mundialização com face humana. Para as mulheres, um dos grupos prioritários para as ações da UNESCO para o referido sexênio, consta que a instituição se comprometeu a incorporar considerações relativas à condição da mulher nas atividades de 
planificação de políticas, programação, execução e avaliação em todos os âmbitos de sua competência, com o objetivo final de promover o pleno exercício de seus direitos e conseguir a igualdade entre homens e mulheres. Avalia-se que o Foro de Dacar, de 2000, é parte integrante da atual dinâmica de mudanças no mundo da educação que, conjuntamente com Relatório Jacques Delors e de uma série de conferências mundiais da UNESCO, têm contribuído para definir o ambicioso programa internacional em torno da vontade de criar, no plano mundial, sociedades de aprendizagem baseadas na educação como processo permanente. Isto tem coincidido, conforme o documento, em um novo interesse pela educação e pelas políticas educativas presente em muitos países. Origina-se do consenso estabelecido em torno da ideia de que a educação desempenha um papel essencial na luta internacional contra a pobreza e a exclusão que, por sua vez, é um dos grandes objetivos do desenvolvimento internacional, definido na Cúpula do Milênio. Foi considerada importante, também, a consciência cada vez maior de que a educação tem um papel essencial na questão do aprender a viver juntos em um mundo em vias de mundialização e cada vez mais interdependente, em particular mediante o fomento da tolerância e o respeito aos valores universalmente compartilhados, aos direitos humanos e às liberdades fundamentais (UNESCO, 2002).

Tendo em vista o conjunto de documentos que dizem respeito à educação, formulado ao longo dos anos de 1990 no âmbito da UNESCO - com participação das várias agências integrantes do sistema $\mathrm{ONU}$-, bem como os documentos relativos à sua programação de trabalho, os documentos de avaliação dos resultados das políticas implementadas nos países-membros passaram a ser assíduos. Dentre estes, o Relatório de Monitoramento Global (2003/2004), intitulado Gênero e Educação para Todos: o salto para a igualdade é um dos principais e avalia os progressos em relação à equidade entre os gêneros na educação. Nele, são apresentadas algumas orientações de políticas públicas direcionadas à educação de meninas e mulheres, frisando que o papel do Estado é importante nas políticas educacionais em pelo menos três aspectos principais: a) criação, por meio de reformas políticas e legislativas, de ambiente favorável à promoção da igualdade de gênero na educação; b) investimento em redistribuição, por intermédio da "[...] alocação de recursos para a educação de mulheres e da introdução de medidas especiais para reduzir as desigualdades"; e c) diminuição do "[...] impacto de choques externos sobre meninas e mulheres, como os efeitos de conflitos, crises econômicas e HIV/AIDS" (UNESCO, 2004).

Do estudo dos documentos acima, depreende-se que, na perspectiva da UNESCO, à educação feminina, são atribuídas, em princípio, as funções de reparação, equalização e qualificação ${ }^{1}$. A função reparadora é designada na medida em que, com a educação feminina, afirma-se restaurar um dos direitos civis negado às vítimas de uma história de exclusão. Assim, esse contingente populacional excluído do sistema de ensino passa a ter o direito à educação pela via das políticas inclusivas, fundamentadas na defesa da igualdade perante a lei. As políticas de gênero, referentes ao atendimento às mulheres, concebidas como grupo prioritário a ser incluído pelas políticas educacionais, são propaladas como tentativa de reparar uma espécie de "dívida social", marcada pela exclusão de mulheres e meninas dos processos educativos formais.

À educação feminina também, é atribuída uma função equalizadora, ela é responsabilizada pela discriminação positiva desse grupo socialmente vulnerável, integrando-o ao sistema educacional. A educação feminina, ao integrar as denominadas políticas de ações afirmativas, assumiria o propósito de ofertar maiores oportunidades àqueles que precisam mais, e isto fomentaria maior equidade social. Cumpriria, portanto, a função equalizadora no que diz respeito às mulheres e meninas ao corrigir distorções na 
aplicabilidade de ações, que, por princípio, deveriam ser iguais para todos.

A função qualificadora da educação feminina, sob a perspectiva da UNESCO, é expressa na proposição de que é necessário "educação ao longo da vida", já que, em uma "sociedade do conhecimento", o acesso e permanência na escola torna-se a garantia para que o princípio da igualdade de oportunidades seja uma realidade. A educação das mulheres é entendida como indispensável para o exercício da cidadania, a capacitação para o mundo do trabalho, a descoberta de seu potencial, desenvolvimento de competências, enfim, para o empoderamento das mulheres.

As ações da UNESCO no âmbito da educação da feminina, como se verificou nos documentos estudados, correspondem: ao estabelecimento de um consenso internacional relativo à necessidade da educação para todos; à priorização da educação das mulheres e meninas constante na sua programação sexenal; e a realização de avaliações nos paísesmembros em relação aos avanços políticos rumo à educação para todos. Neste último aspecto, vem recebendo as contribuições do UNICEF.

\section{A educação de meninas e mulheres para o UNICEF}

A atribuição do UNICEF no decorrer de seu mandato, recebida da Assembleia Geral das Nações Unidas, é "[...] fazer gestões pela proteção dos direitos das crianças, ajudando-as a satisfazer suas necessidades básicas e a expandir suas oportunidades de pleno desenvolvimento" (UNICEF, 2006a). A partir de 1989, por meio de seus Programas de Cooperação com os países, as suas ações visam promover a igualdade de direitos das mulheres e das meninas e apoiar sua plena participação no desenvolvimento político, social e econômico de suas comunidades. Atua em regime de parceria com outras agências da ONU, governos e organizações não governamentais, para atingir a meta do desenvolvimento humano sustentável, adotada pela comunidade mundial, bem como para concretizar a visão de paz e progresso social, contida na Carta das Nações Unidas (UNICEF, 2006a).

A questão da educação de meninas e mulheres, como um dos focos de ação do UNICEF, iniciou-se em 1990, no Encontro Mundial de Cúpula pela Criança, realizado em Nova Iorque (EUA), no qual os chefes de Estados ou governos assumiram o compromisso em favor da sobrevivência e do desenvolvimento das crianças. No evento, foi enfatizado que o fortalecimento do papel desempenhado pela mulher e a garantia de igualdade de direitos trariam benefícios para as crianças (UNICEF, 2006a). Neste evento convocado pelo UNICEF, constatou-se que, dos cem milhões de crianças, em 1990, que não recebiam a educação escolar básica, dois terços eram meninas e meio milhão de mães morriam a cada ano de causas relacionadas ao parto. Estes motivos justificaram um dos compromissos acordados de fortalecimento do papel e da condição da mulher, promovendo o planejamento familiar responsável, o espaçamento entre partos, o aleitamento materno e a maternidade sem riscos. Diante de tais constatações, o UNICEF passou a ressaltar o dever de aprimorar a condição da mulher e seu acesso equitativo à educação, à formação, ao crédito e a outros serviços auxiliares. Conforme as disposições do documento, a promoção da condição da mulher se constitui em valiosa contribuição ao desenvolvimento social e econômico de cada nação, por isso, é imprescindível começar com a menina (ONU, 1990).

Como um dos patrocinadores e articuladores do Movimento Internacional de Educação para Todos, o UNICEF defende a necessidade da educação das mulheres e meninas tal qual foi expressa na Conferência Mundial de Educação para Todos, em Jomtiem, 1990, bem como na Cúpula do Milênio em 2000. Neste sentido, o UNICEF vem 
fazendo avaliações sobre os progressos na área educacional e os avanços rumo à realização dos Objetivos de Desenvolvimento do Milênio (ODM) relativos à mulher e às meninas. Os ODM são: erradicar a extrema pobreza e a fome; atingir o ensino básico universal; promover a igualdade entre os sexos e a autonomia das mulheres; reduzir a mortalidade infantil; melhorar a saúde materna; combater o HIV/AIDS, a malária e outras doenças; garantir a sustentabilidade ambiental; e estabelecer uma parceria mundial para o desenvolvimento (ONU, 2000).

Dentre os principais documentos da instituição em que tais avaliações são realizadas estão: Situação Mundial da Infância 2004: meninas, educação $e$ desenvolvimento, 2004; Situação Mundial da Infância 2006: excluídas e invisíveis, 2006; e Situação Mundial da Infância 2007: mulheres e crianças, o duplo dividendo da igualdade de gênero.

Em Situação Mundial da Infância: meninas, educação e desenvolvimento, publicado em 2004, a assertiva central é que a educação feminina é a ferramenta mais eficiente para o desenvolvimento, ou seja, é a chave para o desenvolvimento. São apresentadas como justificativas as exaustivas repetições dos benefícios que a educação das mulheres e meninas promove na sociedade. Estes benefícios estão relacionados à educação para a próxima geração, haja vista que, quando moças com escolaridade tornamse mães, as chances de enviar seus filhos à escola são muito maiores. Conforme o UNICEF (2004), quando uma sociedade assegura educação para as mulheres, seus filhos são mais saudáveis e poucos morrem, a mortalidade materna diminui e há um espaçamento maior entre os partos. Com base nessas evidências, o UNICEF (2004) defende que a educação das meninas é uma via única para o desenvolvimento.

Em outro documento, Situação Mundial da Infância: excluídas e invisíveis, publicado em junho de 2006, a análise dirige-se aos esforços mundiais encaminhados para a realização dos ODM. Este Relatório enfoca as crianças de comunidades marginalizadas, por serem as que sofrem os maiores abusos contra seus direitos, são excluídas dos serviços, estão desprotegidas pela sociedade e pelo Estado, ou seja, são crianças invisíveis para o olhar oficial, porque não estão inseridas nas estatísticas, nas políticas e nos programas. $\mathrm{O}$ Relatório trata especificamente destas crianças e das formas de incluí-las na Agenda do Milênio. Reafirma que a falta de capacitação da mulher tem como consequência a exclusão de seus filhos, já que as mães são as primeiras responsáveis pelos cuidados das crianças. Em situações em que lhes é privado o acesso a serviços básicos, recursos essenciais ou informação, as crianças são as que sofrem a maior exclusão (UNICEF, 2006b).

No documento Situação Mundial da Infância 2007: mulheres e crianças, o duplo dividendo da igualdade de gênero, publicado em dezembro de 2006, o UNICEF trata das condições de vida das mulheres. Embasa-se, ainda, nos argumentos que a educação das mulheres e meninas, bem como a igualdade de gênero na educação são questões fundamentais para que os ODM se realizem. Contudo, amplia a discussão sobre os benefícios da educação feminina ao expor a importância do papel da mulher nas comunidades e na redução da pobreza. A igualdade de gênero, “[...] não tirará da pobreza apenas as mulheres, mas também suas crianças, suas famílias, suas comunidades e seus países" (UNICEF, 2006c, p. viii). O duplo dividendo que a igualdade de gênero rende é que, ao se beneficiarem as mulheres, beneficiam-se também as crianças. Para o UNICEF (2006c), o impacto que a igualdade de gênero pode gerar na redução da pobreza, na educação e no desenvolvimento sustentável depende do aumento da influência das mulheres na tomada de decisões na família, no local de trabalho e na esfera política. Assim, "[...] aumentar o poder da mulher para dar prioridade à educação de meninas gera resultados positivos que atravessa gerações" (UNICEF, 2006c, p. 27). Destaca, ainda, a 
necessidade da qualificação das mulheres para a formação de redes sociais, a fim de que potencializem os recursos da comunidade em que vivem a favor de seus filhos. Estas redes sociais, explicita o documento, aumentam a influência das mulheres na comunidade, particularmente porque a maior parte do impacto do poder de tomada de suas decisões se concentra na própria comunidade. Além destes benefícios, as redes sociais são fonte importante de apoio moral, motivando as mulheres a tomarem decisões em relação aos cuidados com seus filhos e estão provando serem agentes de mudança social (UNICEF, 2006c).

Da análise dos documentos do UNICEF, depreende-se que, similarmente à UNESCO, este atribui à educação feminina as funções de reparação, equalização e qualificação. A agência reforça que a educação de mulheres e meninas é um sustentáculo para que os demais ODM sejam atingidos. Em sua função reparadora, deve propiciar o acesso das mulheres e meninas à escola, rompendo, assim, com o trágico quadro da discriminação por motivo de gênero, que tem sido o principal fator de pauperismo humano. Afirma, também, ser preciso equalizar as diferenças entre ambos os sexos, garantir a paridade de gênero quanto ao acesso à escola, atingir a igualdade em termos educacionais, o que inclui conteúdos e práticas pedagógicas imunes a estereótipos e preconceitos em relação ao sexo feminino.

No que se refere à função qualificadora da educação feminina, verifica-se que o UNICEF tem reforçado, com muita tenacidade, que tal educação é a chave para evitar a reprodução da pobreza intergeracional, ou como expôs o documento do UNICEF (2004), impedir a "transmissão" da pobreza via qualificação das mulheres para gerirem, mais adequada e eficazmente, seu papel como mães.

É importante salientar que as agências, como UNESCO e UNICEF, particularmente voltadas para a composição de um discurso humanitário que sustenta suas proposições e orientações políticas para a área educacional, estabelecem uma articulação íntima com outras agências da $\mathrm{ONU}$, mais direcionadas às questões econômicas, financeiras e de desenvolvimento regional. Muitos estudos educacionais produzidos após os anos de 1990 apresentam-se como coprodução, sobretudo, entre a UNESCO, o UNICEF e a Cepal. Esta articulação entre agências com especificidades institucionais distintas é significativa quando se analisa tal cooperação com base na perspectiva de que a homogeneização dos discursos em prol da educação se estabeleceu tanto entre as agências consideradas mais preocupadas com as questões sociais, a exemplo o UNICEF e a UNESCO, como nas agências financeiras multilaterais, como o BM, incluindo a Cepal, uma agência de desenvolvimento regional.

No final dos anos de 1980, em conformidade com Coraggio (2000), quando o Fundo Monetário Internacional (FMI) e o BM estavam ocupados em implementar o neoliberalismo economicista via políticas de ajuste, as agências "sensíveis ao social" da ONU (UNESCO, UNICEF e Programa das Nações Unidas para o Desenvolvimento) passaram a argumentar sobre os efeitos negativos de tais políticas na área social. Para o autor, estas agências, em especial o UNICEF, detectaram a necessidade de um "ajuste com rosto humano", defendendo ações em prol dos grupos mais vulneráveis da população, atingidos negativamente pelos resultados dos ajustes estruturais em diversos países da América Latina.

Para Fitoussi e Rosanvallon (1997), as desigualdades chamadas estruturais, que foram herdadas historicamente, passaram a constituírem-se em um problema quando começaram a multiplicar-se e aumentar a probabilidade de se acumularem em determinadas populações. Neste contexto, explicitam Fitoussi e Rosanvallon (1997, p. 9), emergiram, no campo da política moderna, três "perversões fundamentais". A primeira é a 
confusão entre política e bons sentimentos, em que predominam os anúncios e denúncias sobre as mazelas sociais formando um "consenso dos bons sentimentos", que não implicam em políticas efetivas para superá-las. A segunda é o gosto pela políticaespetáculo, na qual o essencial é a exibição de generosidade e mostras de boa vontade, em que a ação apenas multiplica os efeitos dos anúncios sem a aplicação de ações políticas efetivas. Por último, está a simplificação dos problemas. Estas três características assinaladas pelos autores são elucidadoras para se compreender como as agências multilaterais subordinam as questões sociais à mera política dos bons sentimentos e simplificam os problemas mundiais, defendendo a ideia que a educação é a estratégia fundamental para combater os problemas da pobreza, do desemprego, dentre outros.

As análises de Coraggio (1992, p. 23, tradução nossa) corroboram as assertivas dos autores acima, ao referir que o UNICEF tem um estilo "[...] de não antagonizar identificando responsáveis, mas de atribuir a situação social e suas tendências a processos sem sujeito". O estilo do UNICEF, acrescenta o mesmo autor, é a descrição dos resultados dramáticos dos processos sociais que resultam na pobreza, para fazê-los visíveis e, assim, propor "[...] um série de medidas simples e eficazes, de efeito compensatório auto-evidente ou evidenciável mediante estudos empíricos simples" (CORAGGIO, 1992, p. 23, tradução nossa).

Observa-se, portanto, o abandono da análise global dos problemas sociais, detendose em análises que se focalizam em grupos mais vulneráveis da população, definidos como excluídos, sem, contudo, explicitar a produção social da exclusão no capitalismo monopolista. As políticas dos "bons sentimentos" estão intrinsecamente relacionadas à retórica humanitária, com base na qual as agências multilaterais, como o BM e a Cepal, até então dedicadas às questões técnicas do desenvolvimento econômico, estão construindo seu arcabouço teórico e político a fim de justificar a consolidação do ajuste estrutural nos países da América Latina, como abordar-se-á na sequência.

\section{O Banco Mundial e a educação das mulheres}

O Banco Mundial é a principal agência multilateral internacional de financiamento do desenvolvimento social e econômico. Nos relatórios sobre o desenvolvimento mundial, publicados anualmente pelo BM, são expostos, sistematicamente, os caminhos que cada governo deve percorrer para se adequar à agenda para o desenvolvimento econômico e social. Neste sentido, não atua só como agência financeira, mas como autor de recomendações, orientações e projetos políticos e econômicos com o intuito de moldar o desenvolvimento econômico e social dos países "em desenvolvimento", entre eles os da América Latina, de acordo com a sua proposta de desenvolvimento, que vem sendo propalada pelo seu foco na redução da pobreza. As políticas sociais, entre elas a educação, adquirem centralidade estratégica, uma vez que, de acordo com esta agência, é pela educação que o capital humano é incrementado.

A abordagem do BM em relação à pobreza e a retórica utilizada para explicá-la, incorporam, entre outros argumentos, o problema da reprodução intergeracional da pobreza. Nesta discussão, a educação das mulheres e das meninas ganhou relevância em seu repertório discursivo, conforme evidenciado nos documentos produzidos pela agência a partir dos anos de 1990. Neste artigo, os documentos estudados são os seguintes: Relatório sobre o Desenvolvimento Mundial: A pobreza, 1990; Prioridades e Estratégias para a Educação: estudo setorial do Banco Mundial, 1995; Relatório sobre o Desenvolvimento Mundial: A luta contra a pobreza, 2000/2001.

O Relatório sobre o Desenvolvimento Mundial: A pobreza, de 1990, após 
explanação sobre o desempenho econômico de diferentes regiões ao longo do decênio de 1980, bem como suas previsões econômicas para o desenvolvimento das mesmas, expressa a preocupação com as consequências da economia mundial para as pessoas, em particular para os pobres. A pobreza é definida como "[...] a impossibilidade de alcançar um nível de vida mínimo" (BANCO MUNDIAL, 1990, p. 29). As suas recomendações políticas para o combate à pobreza pautam-se em uma estratégia organizada em duas partes. A primeira "[...] consiste em aplicar um modelo de crescimento que garanta o uso produtivo do bem que os pobres possuem em maior abundância: seu trabalho" (BANCO MUNDIAL, 1990, p. iii). A segunda, por sua vez, é a oferta de serviços sociais básicos aos pobres, especialmente a educação primária, atenção básica à saúde e planificação familiar. Defende o Banco Mundial (1990, p. 39) que, se "[...] as famílias tiverem oportunidades seguras de usar proveitosamente sua mão-de-obra e se seus membros forem capacitados, instruídos e saudáveis, certamente estará assegurado um padrão de vida mínimo e a pobreza desaparecerá".

No Relatório de 1990, os estudos apresentados em relação ao empobrecimento mundial demonstraram que o peso da pobreza recai com maior força em certos grupos, em especial nas mulheres. O que significa afirmar que "[...] os dados relativos aos ingressos são insuficientes para dar uma resposta conclusiva, mas as cifras disponíveis sobre saúde, nutrição, educação e participação na força de trabalho mostram que as mulheres com frequência estão em grave situação de desvantagem" (BANCO MUNDIAL, 1990, p. 35). No que se relaciona à pobreza das mulheres, no mesmo Relatório, argumenta-se sobre a eficácia da educação como arma na luta contra a pobreza não só em relação ao aumento da produtividade do trabalho dos pobres. A educação teria outros benefícios importantes, particularmente os gerados pela educação das mães, já que "[...] um ano de educação da mãe tem relação com a diminuição de $9 \%$ na taxa de mortalidade infantil. Os filhos de mães com um maior nível de instrução - sendo as demais características iguais - tendem a ser mais saudáveis" (p. 35).

Tendo a educação como estratégia fundamental para a redução da pobreza, em 1995, o BM produziu o documento intitulado Prioridades e estratégias para a educação, título original: Prioridades y estratégias para la educación: estudio sectorial del Banco Mundial. A ideia basilar nele contida é que a educação possui um papel fundamental na redução da pobreza e, como consequência, no crescimento econômico do país. Como forma de justificar a empreitada da instituição no terreno educacional com base em sua nova política de investimentos setoriais, o referido documento estabelece a relação entre a educação, o crescimento e a redução da pobreza. Nesta análise, sobressaem-se os elementos que permeiam a necessidade de investimento em educação básica, expressão que deve ser entendida como ensino primário. No entanto, o documento salienta que a educação, como forma de investimento em capital humano, por si só não gera crescimento econômico. A geração de crescimento econômico precisa da associação entre capital humano, capital físico e uma economia com mercados competitivos.Tal tipo de economia pressupõe estabilidade macroeconômica, abertura comercial, bom funcionamento dos mercados de trabalho e aporte tecnológico. Este é o ambiente adequado para que o capital humano seja utilizado produtivamente (BANCO MUNDIAL, 1995).

A educação, defende o documento em pauta, contribui para o crescimento econômico pelo incremento da produtividade individual, resultante da aquisição de aptidões, atitudes e acúmulo de conhecimentos. A educação, como um setor prioritário para o investimento, tem duas vantagens, uma relacionada à rentabilidade social, que é superior à rentabilidade privada, e a outra relacionada ao que a agência chama de externalidades. Estas se relacionam à redução da pobreza, particularmente, no que toca à 
questão da saúde e da fecundidade. O efeito da educação na fecundidade se faz sentir por meio do aumento da idade em que as mulheres contraem matrimônio e fazem uso de anticonceptivos. Quanto maior o nível de educação dos pais, em particular da mãe, menor é a mortalidade materna e os filhos são mais saudáveis. Em relação à saúde, explica que há influências da educação dos pais quanto à utilização dos serviços médicos, como atenção pré-natal e consultas, e na modificação dos hábitos higiênicos do grupo familiar. Para o BM (1995), as modificações do comportamento podem resultar de mudanças nas ideias e atitudes e na capacidade de proporcionar melhor nutrição e melhores serviços de saúde a seus filhos. Portanto, a rentabilidade do investimento na educação de mulheres é superior à dos homens quando se trata de mulheres que obtêm emprego. Uma vez que se agregam as externalidades de saúde e fecundidade, os argumentos em favor da educação das meninas resultam ainda mais convincentes, visto que a educação pode romper com a reprodução da pobreza no futuro (BANCO MUNDIAL, 1995).

Após transcorrida uma década desde a publicação do Relatório sobre o Desenvolvimento Mundial em 1990, o BM inseriu novamente a temática sobre a pobreza mundial em 2000 no Relatório sobre o Desenvolvimento Mundial 2000/2001, intitulado A luta contra a pobreza. Nele, argumenta que as causas da pobreza apresentam três dimensões. A primeira é a falta de renda e de recursos para atender às necessidades básicas, como alimento, habitação, vestuário e níveis aceitáveis de saúde e educação. A segunda é a falta de voz e de poder nas instituições estatais e na sociedade. A terceira é a vulnerabilidade a choques adversos que está combinada com a incapacidade de enfrentálos (BANCO MUNDIAL, 2001).

Pautado no conceito de pobreza como "privação de capacidades", o BM (2001, p. 6), compilou três estratégias para combatê-la, que são: "[...] promover oportunidades, facilitar a autonomia e aumentar a segurança". Na estratégia de "facilitar a autonomia", consta o objetivo da promoção da igualdade entre os sexos. Esta tem relevância especial para o BM a ponto de merecer ênfase adicional. Para implementar ações relativas a esta "frente de atuação", o Banco considera imprescindível o fortalecimento das instituições sociais que abrangem os sistemas de parentesco e organizações comunitárias, bem como as redes informais, visto que estes sistemas estão envolvidos nos processos que afetam a pobreza. Nas instituições sociais, a discriminação com base no sexo, etnia, raça, religião ou posição social pode conduzir à exclusão social e manter as pessoas nas "armadilhas da pobreza" por longo prazo. As formas de discriminação constituem-se em barreiras que precisam ser removidas (BANCO MUNDIAL, 2001). Sobre a relação entre discriminação sexual e pobreza, expõe o Relatório 2000/2001, entre outros elementos, que a “[...] desigualdade entre os sexos tem acentuadas repercussões no que se refere ao capital humano da próxima geração, dado que o encargo de gerar e criar os filhos recai em grande parte sobre a mulher" (BANCO MUNDIAL, 2001, p. 123). Para este documento, a mulher que não tem instrução e não exerce poder de decisão em seu lar tem dificuldades em manter seus filhos sadios e produtivos, situação que muda quando as mulheres são mais instruídas.

A questão das mulheres também é inserida nas orientações políticas do Relatório 2000/2001, que contemplam as estratégias para "eliminar as barreiras sociais" e "reforçar o capital dos pobres". Em relação à primeira, expõe que as desigualdades econômicas são fortalecidas pelas barreiras sociais; para removê-las, faz-se necessário adotar enfoques múltiplos. Afirma-se que "[...] o governo pode dar uma contribuição importante se assegurar que os órgãos públicos e outras instituições atendam igualmente a todos os setores da população" (BANCO MUNDIAL, 2001, p. 129). A recomendação é que as instituições precisam mobilizar os grupos excluídos para que estes atuem mais em relação 
a seus direitos e necessidades. Uma das indicações para fazer com que os "excluídos" sejam mais atuantes na sociedade são as políticas de ações afirmativas. Estas políticas são justificadas para compensar as incapacidades que resultam de uma discriminação prolongada. Segundo o BM (2001, p. 130), “[...] para competir na arena política e econômica, as vítimas da discriminação precisam de assistência especial na aquisição de educação, informação e autoconfiança". Na sua visão, tais políticas têm uma função crucial que é "[...] a criação de papéis-modelo que possam alterar noções profundamente arraigadas sobre a diferença de valor e de capacidade de que estão impregnadas as sociedades segregadas" (p. 131).

Observa-se que, do conceito de pobreza pautado na noção de falta de capacidades e liberdade, derivam ideologias que tentam fazer valer a noção de que o que a população pobre mais carece é de oportunidades, escolhas, liberdade e dignidade. A renda para suprir suas necessidades vitais decorre da aquisição de habilidades e aptidões que a fazem aproveitar mais as oportunidades postas pelo mercado.

É no interior destas análises, ou seja, da produtividade gerada pelo capital humano, que a questão da educação das mulheres e meninas é contemplada nos documentos do BM. No entanto, esta produtividade está diretamente vinculada à capacidade reprodutiva das mulheres. Neste sentido, a ênfase dada à educação das mulheres justifica-se pela contribuição do controle à natalidade nos países periféricos. Evitar a gravidez para reduzir o número de filhos, fazendo uso correto dos métodos contraceptivos, é o primeiro argumento que a agência, repetidamente, inclui em suas observações. Para não ficar somente no terreno da fertilidade feminina, agrega a este argumento a questão da maternidade. $\mathrm{O}$ discurso remete-se à educação como principal fator para a redução da mortalidade infantil, já que possibilita às mães alimentar melhor seus filhos e ter acesso aos serviços de saúde. Quanto à educação das crianças, a mulher que recebeu alguns anos de instrução se torna mais apta a incluir seus filhos no sistema de ensino, uma vez que reconhece que a educação formal é necessária para que tenham uma melhor perspectiva de vida. Em decorrência, a mulher instruída pode garantir o incremento do capital humano de seus filhos, que, no futuro, poderão se inserir, sem maiores obstáculos, no mercado de trabalho.

\section{A educação das mulheres e meninas na perspectiva da Cepal}

A Comissão Econômica para a América Latina e Caribe é uma agência da ONU que afirma atuar como um centro de estudos na região e colaborar com os EstadosMembros em diversas instituições locais, nacionais e internacionais pela análise dos processos de desenvolvimento, por meio da formulação, seguimento e avaliação das políticas públicas (CEPAL, 2006). Os documentos produzidos pela Cepal pós 1990 integram, em seu conjunto, orientações políticas para a região latino-americana e caribenha, a fim de retomar o desenvolvimento econômico e social abalado nos anos de 1980 pela "crise da dívida externa".

A orientação institucional para as políticas de desenvolvimento na região latino americana para o período considerado, constante no documento da Cepal Transformação Produtiva com Eqüidade, de 1990, enfoca a educação como parte integrante do novo modelo de desenvolvimento. Considera a formação de recursos humanos na região um requisito indispensável para prover o progresso técnico para a transformação produtiva, pautada no crescimento e equidade social. Neste documento, a Cepal é enfática em afirmar que uma das funções sociais do Estado consiste em direcionar as verbas públicas para o social, utilizando-se de programas sociais, sobretudo aqueles relacionados com a formação 
do capital humano, como a educação.

As orientações políticas da Cepal, contidas no documento acima referido, serviram de guia para a elaboração de vários documentos institucionais no período, entre eles: Educação e conhecimento: eixo da transformação produtiva com eqüidade, 1992; Eqüidade e transformação produtiva: um enfoque integrado, 1996; Eqüidade, desenvolvimento e cidadania, 2000; e Panorama Social da América Latina de 2003.

Em 1992, a Cepal em conjunto com a UNESCO organizaram um compêndio sobre a educação, intitulado Educação e conhecimento: eixo da transformação produtiva com equiidade. Nele enunciam os fundamentos nos quais os países da região devem embasar-se para formular suas políticas educacionais. Estes pressupostos fundam-se na articulação entre educação, conhecimento e desenvolvimento, considerados a tríade central para o projeto da transformação produtiva com equidade. Recomendam-se estratégias para a criação das condições educacionais, de capacitação e de incorporação do progresso científico e tecnológico, que possam transformar as estruturas produtivas dentro de uma progressiva equidade social. Enfatiza-se, sobretudo, que este objetivo só poderá ser alcançado com uma ampla reforma dos sistemas educacionais e de capacitação de mão de obra da região, gerando a capacidade de aproveitamento interno do progresso científico e tecnológico (CEPAL; UNESCO, 1995). Em relação à educação feminina, a Cepal assimila alguns dos temas referentes à educação das mulheres discutidos na Conferência Mundial de Educação para Todos, em Jomtien, 1990, incluindo, como uma das prioridades, a educação das mulheres e das meninas e preconizando a revisão dos materiais didáticos a fim de retirar os conteúdos com estereótipos femininos.

Em Eqüidade e transformação produtiva: um enfoque integrado de 1996, o objetivo da Cepal foi esmerar a proposta da transformação produtiva com equidade. Postula que o investimento em recursos humanos engloba aquelas ações que tendem a facilitar a acumulação de capital humano, como capacitação, educação, nutrição das gestantes e crianças, saúde, entre outras (CEPAL, 1996). Atribui-se ênfase especial na educação e no conhecimento não somente como um serviço social básico, mas como um dos pivôs do progresso técnico. Neste sentido, para conciliar a eficiência com a equidade, é imperativo melhorar a qualidade da educação e assegurar a todos os estratos sociais um acesso similar à educação (CEPAL, 1996). Reafirma que os programas de investimento social são importantes para se romper com a transmissão intergeracional da pobreza. $\mathrm{O}$ argumento é que "[...] as maiores taxas de fecundidade se registram precisamente entre as famílias mais pobres, por sua vez, as mães das famílias pobres são as que têm maiores riscos de gravidez; seus filhos padecem de pior estado nutricional [...]", o que resulta em maiores dificuldades de aprendizagem escolar e as maiores taxas de repetição e de desistência. Consequentemente, “[...] são eles que em maior medida terminam em trabalhos com pouco futuro e de escassa produtividade no setor informal. Desta maneira, se fecha o círculo vicioso da pobreza, que se transmite de geração em geração" (CEPAL, 1996, p. 11). É tarefa das políticas e programas sociais romperem com este círculo vicioso.

No documento Eqüidade, desenvolvimento e cidadania de 2000, a Cepal retoma algumas discussões feitas nos documentos analisados anteriormente, em particular sobre a questão do desenvolvimento econômico. Além da discussão geral sobre o desenvolvimento na América Latina e Caribe, o documento acentua que houve um crescimento da pobreza na região e estabelece uma agenda de desenvolvimento para o século XXI direcionada, especialmente, para a redução da pobreza. A educação é classificada como uma das chaves-mestra para gerar o progresso simultâneo à igualdade, desenvolvimento e cidadania, sendo vital para bloquear a reprodução da pobreza por meio da sua perpetuação de uma geração a outra. A educação tem efeitos abrangentes na sociedade, por melhorar as 
condições de saúde na família e melhorar a mobilidade social e profissional (CEPAL, 2002). As questões referentes à mulher, abordadas no referido documento, objetivam sinalizar o impacto positivo da educação das mulheres sobre o ambiente educacional e a saúde da família e apontar que, embora as mulheres tenham adquirido um melhor nível educacional, ainda continuam a ter sua força de trabalho subvalorizada no mercado de trabalho (CEPAL, 2002).

À semelhança do documento Eqüidade e transformação produtiva: um enfoque integrado (1996), o documento Eqüidade, desenvolvimento e cidadania" (2000) enfatiza o papel crucial da educação contra a reprodução intergeracional da pobreza. A melhora no ambiente educacional nos lares tem por consequência um efeito triplo: "[...] o rendimento educativo das próximas gerações; incide positivamente na saúde reprodutiva e infantil e, por último, a maior mobilidade sócio-ocupacional ascendente dos egressos do sistema educativo" (CEPAL, 2000, p. 101). Quanto “[...] maior nível de educação formal, menor é a probabilidade de ser pobre ou cair na pobreza". A educação também é considerada o principal meio para superar tanto a pobreza como as causas estruturais que a reproduzem, como "[...] baixa produtividade no trabalho, acesso escasso a ferramentas da vida moderna, marginalidade sociocultural, maior vulnerabilidade das famílias no plano da saúde e descontinuidade ou baixos resultados na educação dos filhos" (CEPAL, 2000, p.101).

A questão das mulheres na região latino-americana e caribenha também é analisada pela Cepal em documento intitulado Panorama Social da América Latina de 2003. Neste documento, é abordada, em um dos capítulos, a questão da pobreza e da desigualdade desde uma perspectiva de gênero e as possibilidades da região atingir os ODM. Dentre as análises realizadas, a Cepal (2003) refere que a autonomia econômica das mulheres é um importante meio para desenvolver o que vem sendo designado de empoderamento, ou seja, a capacidade das mulheres tomarem decisões a agirem, fortalecendo "[...] certas dimensões subjetivas que as fazem sentir-se menos vulneráveis" (CEPAL, 2003, p. 164). Daí ser evidente para a Cepal o investimento no empoderamento das mulheres como imprescindível para que os ODM sejam alcançados na região latino-americana e caribenha. Esta região, pondera-se no documento, seria a única do mundo em desenvolvimento que poderia cumprir o terceiro objetivo de desenvolvimento do milênio, atingindo a meta da equidade de gênero na educação. Enfatiza que a eliminação da desigualdade entre homens e mulheres é um dos objetivos que deve guiar as políticas para superar a pobreza na região. A conclusão que o documento apresenta é que a pobreza afeta com maior severidade as mulheres "[...] sem cuja importante contribuição não é possível superar a pobreza da região" (CEPAL, 2003, p. 135).

Dos documentos da Cepal estudados, observa-se a equidade como pressuposto ou princípio articulador das propostas educacionais, que, embora imersas em um discurso humanitário, preocupado com as questões sociais, estão definidas sob os parâmetros de eficiência econômica e técnica. Suas orientações visam atender à população pobre, mediante gastos reduzidos, preparando-a para ser competitiva no mercado laboral e, com isso, engendrar a competitividade da região no mercado internacional.

O princípio da equidade tem sido, desde nos anos de 1990, o pressuposto central para desencadear o desenvolvimento humano. De acordo com Coraggio (2000, p. 40), o desenvolvimento humano tem como sua principal regra "[...] o investimento nas pessoas: "o capital humano"" (grifos do autor), preocupa-se com o desenvolvimento das capacidades das pessoas e sua utilização no campo produtivo. Deste ponto de vista, o desenvolvimento seria “[...] das pessoas, para as pessoas e pelas pessoas" (p. 40).

Tanto o princípio de equidade como o de eficiência econômica não se sustentam sozinhos na esfera das políticas sociais. Eles são complementares, atendendo às questões 
morais e éticas e aos princípios financeiros. A Cepal, consoante aos discursos difundidos pelo BM, trata de consolidar em seus estudos as propostas educacionais advindas da noção de seletividade e focalização das políticas sociais. Os projetos sociais, ao tomarem o lugar das políticas sociais, são defendidos como a forma mais adequada de o Estado minimizar os custos sociais da pobreza. Cabe ressaltar ainda que, consoante ao discurso da educação como elemento essencial para diminuir a pobreza, a questão da participação das mulheres na comunidade e a exortação para que estas se tornem mais influentes nas decisões da família são muito cogitadas no âmbito das análises e recomendações das agências multilaterais. Tais discursos de participação das mulheres nas comunidades são bastante coerentes com os pressupostos de participação da comunidade em geral, propagandeados pela doutrina neoliberal. A receita baseada no empoderamento ${ }^{2}$ e na autogestão da comunidade, entre outras estratégias, emerge como alternativas eficientes para resolver os problemas locais, justamente quando os parcos recursos estatais com o social não dão conta de oferecer os serviços básicos para a população. Portanto, passam a preconizar que os governos devem utilizar-se dos projetos sociais, com tempo de implementação demarcado a priori e dependentes do apoio da comunidade para sua eficácia.

A focalização na perspectiva neoliberal substitui a política de acesso universal pelo acesso seletivo, pela restrição dos beneficiários. Em muitos países que adotam programas de ajuste neoliberal, as políticas sociais praticamente se reduzem a programas de socorro à pobreza absoluta. O que significa dizer que a focalização se caracteriza pela oferta de bens públicos, antes de caráter mais universalizante e considerados direitos sociais, a grupos específicos socialmente vulneráveis e que vivem em situações mais emergenciais.

\section{Considerações críticas}

Dos documentos analisados neste artigo, depreende-se que a educação feminina tem adquirido, a partir dos anos de 1990, um significado mais abrangente, que extrapola o âmbito das questões de gênero, para ser concebida como fundamental para $o$ desenvolvimento econômico e social. Embora a exclusão das mulheres e meninas do sistema educacional seja um fenômeno social há muito denunciado pelo movimento de mulheres e movimentos feministas, foi nos anos de 1990 que esta especificidade educacional foi incorporada com ênfase nas políticas educacionais, sendo que as referidas agências multilaterais foram determinantes para alçá-la ao patamar de prioridade no movimento de educação básica para todos.

A apreensão da funcionalidade atribuída à educação das mulheres e das meninas para o BM, como agência de financiamento multilateral, e para a Cepal, como agência de desenvolvimento regional, revela similaridades com a perspectiva da UNESCO e do UNICEF, consideradas como "agências mais sensíveis ao social". Apesar de serem agências com especificidades próprias, não há divergências entre elas, e sim uma complementaridade entre as mais sensíveis ao social e aquelas dedicadas a ações econômicas, financeiras e a de desenvolvimento regional. Agências da ONU, como o UNICEF e a UNESCO, ao atuarem em áreas que escapam da ação dos bancos e das agências de desenvolvimento, configuram-se como espécie de anteparos ideológicos para aquelas, já que produzem e reproduzem múltiplos discursos relacionados aos baluartes da paz, da solidariedade intelectual e moral da humanidade, que são incorporados pelas agências financeiras multilaterais sem maiores complicações. Neste sentido, os bancos multilaterais assumem as preocupações das agências "mais sensíveis ao social" não só em seus discursos, mas nas suas políticas. Ressalve-se que a inserção da preocupação com questões sociais em suas agendas políticas não significa, em contrapartida, o abandono das 
recomendações de reformas e ajustes econômicos, na medida em que isto não cria limites para o cumprimento de suas funções, ao contrário, veicula uma imagem institucional favorável.

Ao pretender evidenciar a função ideológica da educação feminina, deve-se explicitar, de forma contundente, que, embora o BM e a Cepal, supostamente, adotem uma abordagem "mais humana", toda a retórica em favor do investimento em educação básica e sua importância para o desenvolvimento econômico e social, evidentemente, só podem centrar-se nos benefícios econômicos da educação.

Consoante ao acirramento dos problemas sociais, particularmente os relacionados à pobreza de grandes contingentes populacionais, tem emergido, mundialmente, uma miríade de discursos relativos à educação, impulsionados pelo movimento internacional de educação para todos. Tais discursos colocam a educação no centro da cena quando se trata da discussão do empobrecimento mundial. A ausência de bases educacionais nas populações dos países chamados "em desenvolvimento" é considerada o obstáculo maior que impede estes países de seguirem na senda do desenvolvimento econômico e social. A falta de educação formal, portanto, é apontada como um dos fatores precipitantes do processo de empobrecimento em escala mundial, simplificando que a educação é a fórmula de salvação para o problema da pobreza e, concomitantemente, escamoteando as causas reais da pobreza que afetam não só as mulheres e as crianças, como a maioria da população.

O consenso em torno das proposições sobre a educação formal das mulheres, que se baseia em argumentos estritamente econômicos, ligados especialmente em conter o crescimento demográfico, melhorar a saúde e a nutrição da população, a fim de reduzir a pobreza, é estabelecido por intermédio de uma perspectiva teórica lógica e linear, que obscurece as relações mais gerais que implicam na produção da pobreza. A apreensão imediata desses fenômenos, sem a análise das mediações que eles incorporam em sua manifestação, leva a imputar à educação a única estratégia possível para melhorar as condições econômicas e sociais da população.

As proposições analíticas sobre a pobreza, constantes nos vários documentos produzidos por agências multilaterais, emergem de um modelo de atavismo biológico, ou seja, ao naturalizar o social, naturaliza-se a pobreza, sendo, então, possível entendê-la como algo transmitido "hereditariamente", como se suas características psicológicas, intelectuais e comportamentais pudessem ser repassadas de geração em geração por mães analfabetas, incultas e não educadas. Esta abordagem do capital em relação à pobreza representa o reducionismo que caracteriza a visão neoliberal e que, evidentemente, não explica o caráter antagônico da acumulação capitalista. Reproduz, portanto, o pensamento fetichizado, sendo incapaz, em decorrência de limites da consciência que traduz a perspectiva de uma determinada classe social, de explicar as determinações sociais e históricas da pobreza, tratando-a como objeto em si ao naturalizar fenômenos que são sociais e abstraindo as relações societárias em presença. É essa visão reificada que naturaliza e fragmenta a leitura da realidade social e subsidia as políticas de gênero destinadas à educação feminina, concebendo-a como o modelo para romper com o círculo vicioso e intergeracional da pobreza, para a promoção da equidade social, da inclusão escolar e do empoderamento das mulheres. O raciocínio presente é que, como consequência da inclusão escolar, haveria a inclusão na vida cidadã e, com ela, o acesso ao mercado de trabalho.

Desvela-se, portanto, que, além das funções de reparação, equalização e qualificação, há uma funcionalidade ideológica da educação feminina, a qual, a partir dos anos de 1990, vem sendo utilizada como uma das sustentações da retórica da qual se 
nutrem a política dos bons sentimentos e a política espetáculo. Torna-se instrumento essencial para a reprodução do discurso de que os problemas da pobreza podem ser "facilmente" resolvidos por meio da educação, o que permite simplificar uma grave contradição estrutural do capital, que é a multiplicação da pobreza dos seres humanos mediante o movimento de reprodução, acumulação e expansão do capital. A compartimentalização dos problemas sociais, efetivada por meio de grupos específicos (mulheres, índios, jovens, crianças, população rural, entre outros), e a consequente seletividade e focalização das políticas sociais nesses grupos da população condizem com os preceitos políticos neoliberais, que se utilizam dos argumentos da equidade e da eficiência para direcionar as políticas sociais, entre elas a educação.

É justamente pela incapacidade em tratar a pobreza e seu crescimento descontrolado como fenômeno precípuo à dinâmica da acumulação capitalista que as estratégias de combate à pobreza, consolidadas pelas agências multilaterais, resultam limitadas para a consecução dos seus objetivos propalados. A explicação de Mészáros (2002) é extremamente importante para se compreender as políticas sociais, engendradas nesta nova fase do capitalismo monopolista com suas contradições que se revelam mais intensas e predatórias, que implicam ações assistencialistas e focalizadas. Conforme o mesmo autor, o sistema do capital não é capaz de tratar as causas como causas, não considerando suas implicações de longo prazo. Adverte Mészáros (2002, p. 175) que esta condição do capital não é uma dimensão passageira, e sim uma dimensão estrutural, visto que o capital está voltado para sua expansão que, “[...] em suas necessárias ações remediadoras, deve procurar soluções para todos os problemas e contradições gerados em sua estrutura por meio de ajustes feitos estritamente nos efeitos e nas conseqüências".

\section{Considerações finais}

Ao concluir, considera-se importante fazer uma ressalva, para que o posicionamento assumido neste artigo não seja entendido como negação absoluta de qualquer espécie de políticas sociais de ações afirmativas e de políticas públicas de gênero. Não há como negar que estas, historicamente, representam um avanço político conquistado pelo movimento de mulheres, já que suas reivindicações, pouco a pouco, são assimiladas pelo aparato político estatal, o que abre e amplia seus espaços de luta. A oposição crítica está focalizada nas políticas alinhadas aos princípios neoliberais, as quais resultam na destruição das citadas conquistas históricas.

O ponto de vista defendido neste texto é que se deve batalhar por políticas que mantenham o sentido público da educação, a materialização dos direitos sociais com políticas universalistas e duradouras. Destarte, é tarefa prosseguir, de forma crítica, na luta por políticas voltadas à concretização do princípio da igualdade material e social. Estas precisam ser arduamente defendidas a fim de impedir que a histórica luta das mulheres por políticas sociais efetivas não se alinhem, de forma simbiótica, aos interesses neoliberais de políticas de governo focalizadas e compensatórias.

\section{Referências}

ARRIAGADA, Irma. Breve guia para la aplicación del enfoque de capital social en los programas de pobreza. Santiago de Chile: CEPAL, 2006.

BANCO MUNDIAL. Informe sobre el desarrollo mundial 1990: la pobreza. Washington, DC: BM, 1990. 
Prioridades y estrategias para la educación: estudio sectorial del BM. Versión preliminar. Washington, DC: BM, 1995.

Relatório sobre o desenvolvimento mundial 2000/2001: luta contra a pobreza. Washington, DC: BM/Oxford University Press, 2001.

CARNOY, Martin. Mundialização e reforma na educação: o que os planejadores devem saber. Brasília, DF: UNESCO Brasil, IIPE, 2003.

CEPAL. Transformación productiva com equidad. Santiago do Chile: CEPAL, 1990.

Equidade e transformação produtiva: um enfoque integrado. Santiago do Chile: CEPAL, 1996.

Equidad, desarrollo y ciudadania. Santiago do Chile: CEPAL, 2000.

Equidade, desenvolvimento e cidadania. Rio de Janeiro: Campus, 2002.

2003.

Panorama social da América Latina 2002/2003. Santiago do Chile: CEPAL, abr. 2006.

Informação histórica. Disponível em: 〈http://www.eclac.org>. Acesso em: 10

CEPAL/UNESCO. Educação e conhecimento: eixo da transformação produtiva com eqüidade. Brasília: IPEA/CEPAL/INEP, 1995.

CORAGGIO, José Luis. Economía y educación en América Latina (notas para una agenda para los 90). Papeles del CEAAL, Santiago do Chile, n. 4, 1992. Disponível em: $<$ http://www.coraggioeconomia.org/jlc/archivos\%20para\%20descargar/Econom\%EDa\%20 y\%20Educaci\%F3n\%20en\%20AL.pdf>. Acesso em: 20 dez. 2011.

Es posible pensar alternativas a la política social neoliberal. Nueva sociedad, Venezuela, n. 164, p. 52- 59, nov./dez. 1999.

Desenvolvimento humano e educação. 3. ed. São Paulo: Cortez, 2000.

DELORS, Jacques. Educação: um tesouro a descobrir. 4. ed. São Paulo: Cortez; Brasília, DF: MEC: UNESCO, 2000.

FITOUSSI, Jean-Paul; ROSANVALLON, Pierre. A nova era das desigualdades. Oeiras, Portugal: Celta, 1997.

MÉSZÁROS, István. Para além do capital. São Paulo: Boitempo; Campinas, SP: Editora UNICAMP, 2002.

ONU. Declaração mundial sobre a sobrevivência, a proteção e o desenvolvimento das crianças nos anos 90. Nova Iorque, 1990. Disponível em: <http://www.abmp.org.br/textos/4136.htm>. Acesso em: 9 jan. 2011.

Declaración del milênio. Nueva York: Naciones Unidas, 2000.

SHIROMA, Eneida Oto; CAMPOS, Roselane Fátima; GARCIA, Rosalba M. Cardoso. Decifrar textos para compreender a política: subsídios teórico-metodológicos para análise de documentos. Perspectiva, Florianópolis, v. 23, n. 2, p. 427-446, jul./dez. 2005.

SOARES, Leôncio. Educação de jovens e adultos. Rio de Janeiro: DP\&A, 2002.

UGÁ, Viviam Dominguez. A categoria "pobreza" nas formulações de política social do BM. Revista de Sociologia Política, Curitiba, n. 23, p. 55-62, nov. 2004. 
UNESCO. Declaração mundial de educação para todos. Plano de ação para satisfazer as necessidades básicas de aprendizagem. Tailândia, 1990.

Conferencia General. Estratégia a Plazo Médio: 2002-2007. Paris: UNESCO, 2002. Disponível em: <http://unesdoc.UNESCO.org/images/0012/001254/125434s.pdf>. Acesso em: 5 jan. 2006.

Relatório de monitoramento global de EPT 2003/4: educação para todos: gênero e educação para todos: o salto para a igualdade. São Paulo: Moderna, 2004.

UNESCO/CONSED. Educação para todos: o compromisso de Dakar. Brasília, DF: UNESCO/CONSED. Ação Educativa, 2001.

UNICEF. Situação mundial da infância 2004: meninas, educação e desenvolvimento. New York: UNICEF, 2004. 2 jun. 2006.

Histórico. 2006a. Disponível em: <http://www.UNICEF.org/brazil >. Acesso em:

Situação mundial da infância 2006: excluídas e invisíveis. New York: UNICEF, 2006b. Disponível em: <http://www.UNICEF.org/brazil/pt/sowc2006.pdf>. Acesso em: 10 jun. 2011.

Situação mundial da infância 2007: mulheres e crianças, o duplo dividendo da igualdade de gênero. New York: UNICEF, 2006c. Disponível em: <http://www.UNICEF.org/brazil/pt/sowc07.pdf>. Acesso em: 23 dez. 2011.

Notas:

\footnotetext{
${ }^{1}$ A fundamentação para a discussão dessas funções foi encontrada no Parecer CEB 11/2000, referente às Diretrizes Curriculares Nacionais para a Educação de Jovens e Adultos (SOARES, 2002).

2 Termo definido por Arriagada (2006, p. 53, tradução nossa) como o “[...] processo social mediante o qual se adquire poder, tanto para controlar os recursos externos como para acrescentar as habilidades individuais e coletivas e o bem-estar dos membros de uma sociedade".
}

$\begin{array}{ll}\text { Recebido em: } & 25 / 01 / 12 \\ \text { Aprovado em: } & 27 / 02 / 12\end{array}$ 